\title{
ANÁLISE DAS MUDANÇAS DOS PARÂMETROS FÍSICOS DA SUPERFÍCIE DERIVADOS DAS QUEIMADAS NO ESTADO DE RONDÔNIA
}

Analysis of changes in physical parameters of surface derived from biomass burning in Rondônia State

\author{
FRANCIELLE DA SILVA CARDOZO ${ }^{1}$ \\ GABRIEL PEREIRA ${ }^{2}$ \\ YOSIO EDEMIR SHIMABUKURO ${ }^{1}$ \\ ELISABETE CARIA MORAES ${ }^{1}$
}

\author{
${ }^{1}$ Instituto Nacional de Pesquisas Espaciais - INPE \\ Caixa Postal 515 - 12227-010 - São José dos Campos - SP, Brasil \\ ${ }^{2}$ Universidade Federal de São João del- Rei - UFSJ \\ Departamento de Geociências. Rodovia BR-494 - km 194 - 196 \\ São João del Rei - MG. 36301360 \\ \{cardozo, yosio, bete\}@dsr.inpe.br; pereira@ufsj.edu.br
}

\section{RESUMO}

O objetivo principal deste trabalho consistiu na avaliação dos impactos das queimadas na modificação da temperatura do solo e da radiação de ondas curtas no Estado de Rondônia nos anos de 2000 a 2011, utilizando o RegCM4 para a modelagem dos dados. Este modelo necessita da entrada de dados como o uso e cobertura da terra (com e sem queimadas) e parâmetros físicos como o albedo da superfície (separados em radiação fotossinteticamente ativa e reflectância no infravermelho próximo e médio), o índice de área foliar e a fração de cobertura vegetal. Assim, os mapas de uso da terra foram atualizados a partir do produto MCD12A1 do sensor Moderate Resolution Imaging Spectroradiometer (MODIS). Para o mapeamento das queimadas foram utilizadas imagens dos produtos MOD09 e MYD09 do sensor MODIS, a partir do Modelo Linear de Mistura Espectral (MLME), segmentação das imagens fração sombra e edição manual. Os dados do albedo da superfície e da fração de cobertura vegetal foram coletados em campo com o FieldSpec Pro e o índice de área foliar foi obtido dos produtos MYD15A2 e 
MOD15A2 do sensor MODIS. Os resultados indicaram que as queimadas apresentam uma variabilidade significativa no Estado de Rondônia, com destaque para os anos de 2005, 2010 e 2004 e ocorrem frequentemente em áreas que já possuem algum tipo de uso, como áreas de extrativismo vegetal, pecuária de animais de grande porte e cultivos permanentes diversificados. Os valores de albedo apresentam uma diminuição de $16 \%$ na ocorrência de uma queimada, fator que provoca modificações no balanço de radiação de ondas curtas. Estas modificações ocasionam o aumento da temperatura do solo, que podem atingir valores máximos diários superiores a $10^{\circ} \mathrm{C}$, provocando alterações significativas em diversas variáveis climatológicas que podem impactar a climatologia local e regional.

Palavras-chave: Queimadas; Modelagem; RegCM4; Impactos.

\begin{abstract}
The main objective of this work is to analyze the impacts in soil temperature and short-wave radiation balance derived from biomass burning in Rondônia State for 2000-2011 years, using RegCM4 for meteorological modeling. This model requires some input data such as land use and land cover maps (with and without burned areas) and physical parameters such as the surface albedo (separated in photosynthetic active radiation and in shortwave infrared reflectance), leaf area index and the fraction of vegetation cover. Thus, the land use and land cover maps were updated from MCD12A1 product of Moderate Resolution Imaging Spectroradiometer (MODIS) sensor. The MOD09 and MYD09 products of MODIS were utilized for the burned areas mapping, obtained from the Linear Spectral Mixture Model (SLMM), segmentation of shadow fraction images and manual editing. The surface albedo and the fraction of vegetation cover data were collected in the fieldwork with FieldSpec Pro equipment and leaf area index was obtained from MYD15A2 and MOD15A2 of MODIS products. The results indicated that the burned areas exhibit significant variability in Rondônia State, especially in 2005, 2010 and 2004 years, and these burnings occur in majority in areas that already have some type of use (areas of vegetation extraction, large animals livestock areas and diverse permanent crops). The albedo values showed a decrease of $16 \%$ with the occurrence of a fire, a factor that causes changes in short-wave radiation balance. These changes occasioned the elevation of soil temperature, which can reach maximums values of $10^{\circ} \mathrm{C}$ per day, resulting in significant changes in different climatic variables that may alter the local and regional climate.
\end{abstract}

Keywords: Biomass Burning; Modeling; RegCM4; Impacts.

\title{
1. INTRODUÇÃO
}

No Brasil, especialmente na região Amazônica, as atividades ligadas ao uso da terra como o desmatamento, a renovação de pastagens, o controle de pestes e o processo de produção e expansão agropecuária são realizados principalmente a 
partir das práticas que utilizam a queima da biomassa (SAMPAIO et al., 2007; CARDOSO et al., 2008; MARENGO et al., 2010).

O período de atuação das queimadas na Região Amazônica ocorre anualmente durante a estação seca, principalmente durante os meses de junho a outubro. Nessa época a vegetação torna-se mais suscetível ao fogo devido ao clima mais seco e à baixa umidade, e fatores como o tipo de biomassa, temperatura do ar, umidade e ventos determinarão a origem e a permanência de uma queimada na superfície (CRUTZEN e ANDREAE, 1990; FREITAS et al., 2005; VAN der WERF et al., 2006; FEARNSIDE et al., 2009).

Porém, as queimadas consomem grandes quantidades de biomassa e causam diversos impactos no ambiente, principalmente devido à liberação de gases traço e aerossóis para a atmosfera. Esses gases provocam o espalhamento e a absorção da radiação solar incidente, que causam o aquecimento da superfície terrestre e da atmosfera, um mecanismo conhecido como "forçante radiativa direta" (DRF), que define o grau de influência de um determinado gás na intensificação do efeito estufa (CHARLSON et al., 1992; HOUGHTON et al., 2001). Ainda, a absorção da radiação solar pelas cinzas negras e pelos carvões depositados após a ocorrência do fogo reduz o albedo da superfície, ocasionando aumento na temperatura da superfície e alterações nos fluxos de calor latente e sensível (PEREIRA et al., 2000; LIANG, 2000; BOWMAN et al., 2009).

Neste contexto, a queimada é considerada como um dos principais agentes modificadores da paisagem devido à devastação imposta em extensas áreas da superfície. Assim, o Brasil é considerado como um dos grandes emissores de aerossóis e gases traços associados ao uso da terra, além de representar um grande potencial de emissões futuras devido às suas vastas áreas remanescentes de florestas tropicais (FEARNSIDE et al., 2009).

Diante do exposto, verifica-se que o estudo e o mapeamento das áreas queimadas na região Amazônica são de fundamental importância para a obtenção de estimativas precisas das alterações ambientais, principalmente por permitir o monitoramento das mudanças no uso e cobertura da terra e fornecer os dados de entrada necessários para a representação das características físico-químicas e biológicas em modelos atmosféricos, tornando possível a avaliação dos impactos na superfície e na atmosfera.

Os modelos numéricos vêm sendo utilizados em uma grande variedade de estudos nas últimas décadas, e dentre eles, podemos citar o RegCM, um modelo regional utilizado em estudos que envolvem a análise e variações de precipitação, temperaturas e do clima em geral, principalmente quando relacionados com as mudanças no uso e cobertura da terra (LIU et al., 1996; DRUYAN et al., 2002; CUADRA e ROCHA, 2006; ROCHA, 2009).

Dentre alguns estudos realizados utilizando o RegCM, podem-se citar o de Liu (2005), que utilizou o modelo para analisar os impactos da queima da biomassa no balaço de radiação e no clima da América do Sul. Os resultados mostraram que o modelo indicou com consistência que os gases traços e aerossóis na Amazônia 
afetam o balanço de radiação de ondas curtas e que o impacto é reduzido devido à retroalimentação da atmosfera, que é significativa na região da Amazônia. Zhang (2005) estudou como a queima de biomassa em larga escala na região Amazônica pode influenciar a transição da estação seca para a chuvosa, assim, foram forçadas algumas simulações de dados sobre a forçante radiativa de fumaça com dados do MODIS na estação de transição (Agosto para Novembro de 2005). Os resultados mostraram que as forçantes de fumaça diretas e semi-diretas influenciam na precipitação e nas suas relações com as condições atmosféricas e da superfície durante a época da transição, e que essas mudanças são sensíveis com a distribuição vertical dos aerossóis.

Outro estudo refere-se à Tummon et al. (2010), que utilizaram o modelo para simular os efeitos radiativos diretos e indiretos da queima de biomassa e dos aerossóis de poeira sobre o Sul da África durante a estação de inverno. Os resultados indicaram que a forçante radiativa na superfície em dias de céu claro diminuíram nas regiões que apresentavam queimadas, resultando na diminuição dos fluxos turbulentos e na temperatura da superfície (sem levar em consideração a alteração do albedo e outros parâmetros físicos) e que a absorção radiativa pelos aerossóis das queimadas resultaram no aquecimento diabático da atmosfera em uma taxa acima de $1^{\circ} \mathrm{C}$ por dia.

Pereira (2012) verificou o impacto nas simulações numéricas do RegCM4 oriundas da atualização de mapas do uso e cobertura da terra e suas respectivas características físico-químicas e biológicas, além da validação dos dados do Tropical Rainfall Measuring Mission (TRMM). Como na maioria dos modelos regionais e de previsão do tempo e clima, os mapas de uso e cobertura da terra encontram-se defasados, e este fator influencia nos resultados das simulações. Os resultados mostraram que a comparação dos dados de precipitação mensal estimada pelo TRMM com as 183 estações meteorológicas espalhadas pelo Brasil apresentaram uma concordância de aproximadamente 97\%. Ainda, com a atualização do uso e cobertura da terra para o ano de 2007 utilizado pelo modelo de superfície BATS, os resultados obtiveram uma melhora de $10 \%$ da simulação da precipitação, além de uma boa concordância em relação à temperatura máxima e mínima, com valores próximos ao esperado.

Tesfaye et al. (2013) avaliaram o desempenho das propriedades ópticas dos aerossóis (POA) no modelo RegCM4, acoplado a um esquema antropogênico de poeira no deserto na África do Sul. A validação foi realizada a partir da comparação com dados dos perfis de coeficientes de extinção dos aerossóis, profundidade óptica dos aerossóis e albedo com observações dos sensores AERONET, LIDAR, e MISR. Os resultados mostraram que a simulação da POA apresentaram valores de acordo com o desvio padrão comparado com o AERONET e $\pm 25 \%$ com observações do MISR. Em relação ao LIDAR, o modelo apresentou um bom desempenho na captura dos perfis de extinção de aerossóis, indicando uma boa habilidade na reprodução das principais características no que concerne aos aerossóis na área de interesse. 
Fuentes-Franco et al. (2014) avaliaram a habilidade do modelo RegCM4 na obtenção dos padrões médios e da variabilidade interanual da temperatura e precipitação no México, a partir de comparações com 27 anos de observações originadas por reanálises. Os resultados indicaram que o RegCM4 reproduz adequadamente os padrões espaciais médios da precipitação e temperatura sazonal, associadas com a variabilidade interanual. O principal erro encontrado consistiu na superestimativa da precipitação em regiões montanhosas, e que o desempenho do modelo denotou qualidade suficiente não apenas para o estudo da precipitação e temperatura, mas também pode ser utilizado para a estimativa de outras variáveis climatológicas.

Desta forma, o objetivo principal deste trabalho consiste na avaliação dos impactos das queimadas na modificação da temperatura do solo e da radiação de ondas curtas no Estado de Rondônia nos anos de 2000 a 2011, utilizando o RegCM4 para a simulação das interações superfície-atmosfera.

\section{2. ÁREA DE ESTUDO}

A área de estudo abrange o Estado de Rondônia, localizado nas coordenadas geográficas $09^{\circ} 45^{\prime}$ e $8^{\circ} 00^{\prime}$ de latitude sul; $66^{\circ} 50^{\prime}$ e $59^{\circ} 50^{\prime}$ de longitude oeste, conforme Figura 1. O Estado possui área total de $237.576 \mathrm{~km}^{2}$, fazendo divisa com o Estado do Amazonas a norte, Acre a oeste, Mato Grosso à leste e sul e com a Bolívia à oeste e sul. Na Figura 1 pode-se visualizar os locais de coleta do fator de reflectância espectral de diversos alvos da superfície, representados pelos círculos em preto, obtidos durante o trabalho de campo realizado no período de 24 a 31 de agosto de 2013. Ressalta-se que para cada local indicado, diversas coletas foram realizadas no entorno do ponto.

A ocupação do Estado de Rondônia ocorreu a partir da década de 1960, com o estabelecimento de leis que promoveram o desenvolvimento socioeconômico da Amazônia brasileira. Neste conjunto de leis, surgiram planos para a inserção da agricultura, iniciando então o processo de intervenção antrópica sobre a floresta (SILVA et al., 2005). Assim, a política de colonização implantada na época atraiu a população para o Estado, proporcionando o maior crescimento populacional do país na década de 80 , com um aumento de $324 \%$. Dentre as políticas de ação que ocasionaram o interesse migratório, pode-se ressaltar o crescimento da indústria madeireira, que aliadas às melhorias nas estradas propiciaram maior acesso aos agricultores e camponeses às áreas até então inacessíveis; o desmatamento, que começou a se expandir para o interior do Estado, até então concentrado na área central; e as queimadas, causadas pela população no manejo de pastagens e áreas agrícolas (BATISTA, 2001). 
Figura 1 - Localização da área de estudo. Imagem sensor MODIS, composição 1B2G6R, dia 11/08/2010.

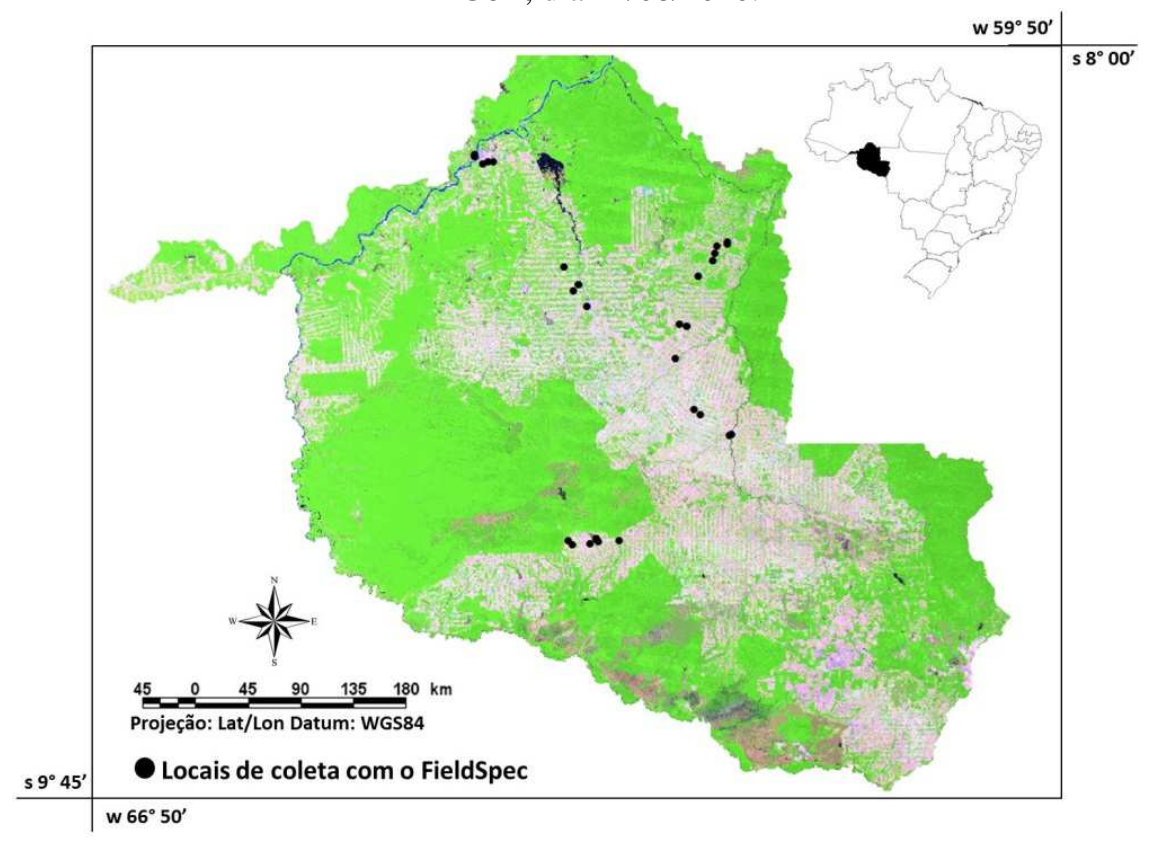

De acordo com dados atualizados do uso da terra do IBGE (2011), Rondônia pode ser caracterizada, de uma forma geral, por unidades de conservação de proteção integral, associadas às áreas florestais, áreas graníferas e cerealíferas e pecuária de animais de grande porte; por unidades de conservação de uso sustentável, incluindo áreas florestais, áreas graníferas e cerealíferas e pecuária de animais de grande porte; por áreas campestres, relacionadas à unidades de conservação de proteção integral, unidades de conservação de uso sustentável e pecuária de animais de grande porte; pelo extrativismo vegetal em área florestal; por áreas graníferas e cerealíferas; pela pecuária de animais de grande porte, associadas com cultivos permanentes diversificados; por terras indígenas, que se relacionam com áreas campestres, áreas florestais, unidades de conservação de uso integral e sustentável e por áreas urbanas.

\section{METODOLOGIA}

\subsection{O modelo RegCM4}

O RegCM é um modelo climático regional, considerado como um modelo numérico de área limitada, fator que permite uma melhor representação dos fenômenos meteorológicos. Ele é baseado no modelo numérico Mesoscale Model 
versão 4 (MM4), desenvolvido por Dickinson et al. (1989) e Giorgi (1989). O RegCM4 possui dois modelos de superfície, o Biosphere-Atmosphere Transfer Scheme (BATS), desenvolvido por Dickinson et al. (1986) e o Community Land Model (CLM), desenvolvido por Oleson (2004), além de parametrizações com esquemas de convecção de cúmulos, umidade, condições iniciais e de contorno lateral, fluxos oceânicos e gradiente de pressão.

A definição do modelo de superfície baseou-se na capacidade de modificação do uso e cobertura da terra (UCT) e dos parâmetros físicos como o albedo da superfície, o índice de área foliar e a fração de cobertura vegetal (necessários na simulação e coletados em campo). Neste contexto, optou-se por utilizar o BATS, que possui 20 classes de UCT, apresenta as interações entre a superfície e a atmosfera e simula a influência da vegetação e umidade do solo nas trocas de momentum, energia e vapor d'água. Para atualizar o mapa de UCT, defasado desde 1992, utilizou-se os dados do produto MCD12A1 do sensor Moderate Resolution Imaging Spectroradiometer (MODIS), que representa o Uso e Cobertura da Terra para cada ano analisado (2000-2011), com resolução espacial de $500 \mathrm{~m}$. Desta forma, para cada ano, foram realizadas duas rodadas: I) com o dado de UCT proveniente do produto MCD12A1 (denominada neste trabalho de controle); II) com o dado de UCT do MCD12A1 com as áreas queimadas do respectivo ano (denominada neste trabalho de queimada).

Neste trabalho, definiram-se como parâmetros iniciais do modelo: I) início da simulação dia 01 de julho, final da simulação dia 01 de novembro para o período de 2000 a 2011; II) 224 pontos na coordenada x (longitude), 224 pontos na coordenada y (latitude) e 18 pontos em z (altitude), resolução espacial de $5 \mathrm{~km}$ e início da grade em $11^{\circ} \mathrm{S}$ e $63^{\circ} \mathrm{W}$. Ainda, para as configurações adicionais do modelo, empregaramse as configurações mais adotadas na literatura: I) esquema de condições iniciais proposto por Holtslag et al. (1990), descrito na Equação 1; II) esquema de convecção cúmulos desenvolvido por Grell et al. (1994), descrito na Equação 2; III) Momentum horizontal proposto por Grell et al. (1994), descrito nas Equações 3 e 4; e IV) Dados de entrada que são assimilados no modelo provenientes do ERAInterim.

$$
F_{c}=-k w_{t} z\left(1-\frac{z}{\frac{R_{i c r}\left[u(h)^{2}+v(h)^{2}\right]}{\left(g / \theta_{s}\right)\left[\theta_{v}(h)-\theta_{s}\right]}}\right)^{2}\left(\frac{\delta C}{\delta z}-\left(C \frac{\phi_{c}^{0}}{\left.w_{t} \frac{R_{i c r}\left[u(h)^{2}+v(h)^{2}\right]}{\left(g / \theta_{s}\right)\left[\theta_{v}(h)-\theta_{s}\right]}\right)}\right)\right.
$$

$\mathrm{Na}$ equação $1, \mathrm{k}$ representa a constante de Karman, $\mathrm{w}_{\mathrm{t}}$ representa a velocidade turbulenta convectiva, h é a altura da camada limite planetária, $\mathrm{C}$ é uma constante $(8,5), \phi_{c}^{0}$ representa a temperatura da superfície ou o fluxo de vapor de água, u(h) e $\mathrm{v}(\mathrm{h})$ são as componentes do vento, $\theta_{v}$ é a temperatura potencial virtual na altura da 
camada limite planetária, g é a gravidade, $\mathrm{R}_{\mathrm{icr}}$ é derivado do valor crítico de Richardson, $\theta_{\mathrm{s}}$ representa a temperatura próxima à superfície.

$$
P^{C U}=I_{1}\left(\frac{A B E^{\prime \prime}-A B E}{N A \Delta t}\right)(1-\beta)
$$

$\mathrm{Na}$ equação $2, \mathrm{I}_{1}$ representa a corrente ascendente normalizada, ABE é a energia flutuante disponível para convecção, ABE" é o total de energia flutuante disponível para convecção em adição à energia flutuante originada por processos não-convectivos durante determinado intervalo de tempo $(\Delta \mathrm{t})$ e NA é a taxa de alteração de $\mathrm{ABE}$ em relação à massa de fluxo ascendente.

$$
\begin{aligned}
& \frac{\delta p * u}{\delta t}=-m^{2}\left(\frac{\delta p^{*} u u / m}{\delta x}+\frac{\delta p * v u / m}{\delta y}\right)-\frac{\delta p^{*} u \sigma}{\delta \sigma}-m p *\left[\frac{R T_{v}}{\left(p^{*}+p_{t} / \sigma\right.} \frac{\delta p^{*}}{\delta x}+\frac{\delta \phi}{\delta x}\right]+f p^{*} v+F_{H} u+F_{V} u \\
& \frac{\delta p^{*} v}{\delta t}=-m^{2}\left(\frac{\delta p^{*} u v / m}{\delta x}+\frac{\delta p^{*} v v / m}{\delta y}\right)-m p *\left[\frac{R T_{v}}{\left(p^{*}+p_{t} / \sigma\right)} \frac{\delta p^{*}}{\delta y}+\frac{\delta \phi}{\delta x y}\right]+f p^{*} u+F_{H} u+F_{v} v
\end{aligned}
$$

Nas equações 3 e 4 , u e v representam as componentes zonal e meridional do vento, respectivamente, $\mathrm{T}_{\mathrm{v}}$ é a temperatura virtual, $\Phi$ representa a altura geopotencial, f representa o efeito coriolis, $\mathrm{R}$ é a constante do gás para o ar seco, $\mathrm{m}$ é o fator de escala para a projeção adotada (Mercator), $\sigma$ (coordenada sigma) $=$ $\mathrm{d} \sigma / \mathrm{dt}, \mathrm{F}_{\mathrm{H}}$ e $\mathrm{F}_{\mathrm{V}}$ representam os efeitos da difusão horizontal e vertical e $\mathrm{p}^{*}=\mathrm{ps}$ (pressão na superfície) - pt (pressão em determinado nível).

\subsection{Dados Adicionais Utilizados pelo RegCM4}

\subsection{1 Áreas Queimadas}

Para modelar os impactos das queimadas na superfície pelo modelo RegCM4, o mapeamento foi realizado a partir da utilização de imagens do sensor MODIS, referente aos produtos MOD09GA, que representa a reflectância espectral da superfície, possui 7 bandas e resolução espacial de $500 \mathrm{~m}$, e o MODO09GQ, que possui 2 bandas e resolução espacial de $250 \mathrm{~m}$, ambos com resolução temporal de 1 dia. As imagens utilizadas englobaram os tiles V09, V10, H11 e H12, que abrange o Estado de Rondônia, e o período utilizado consistiu nos meses de junho a novembro dos anos de 2000 a 2011, ou seja, todas as imagens disponíveis durante este período. As imagens que possuíam muitas nuvens e que apresentavam uma má qualidade radiométrica foram descartadas, sendo que ao final foram utilizadas 835 imagens.

Primeiramente, foi realizada a conversão dos produtos MODIS em Hierarchical Data Format (HDF) para o formato Geotiff a partir da ferramenta MODIS Reprojection Tool (MRT), onde foram realizados os mosaicos dos 4 tiles que englobam o Estado de Rondônia e, posteriormente, foi gerado o recorte da área 
de estudo, originando imagens com 7 bandas $(459-479 \mathrm{~nm} ; 545-565 \mathrm{~nm} ; 620$ $670 \mathrm{~nm} ; 841-876 \mathrm{~nm} ; 1230-1250 \mathrm{~nm} ; 1628-1652 \mathrm{~nm}$ e $2105-2155 \mathrm{~nm}$ ) e 250 $\mathrm{m}$ de resolução espacial. Após essa etapa foi utilizado o Modelo Linear de Mistura Espectral (MLME), com o intuito de gerar a fração sombra, que realça os alvos de baixa refletância representados pelas áreas queimadas, reduzindo, desta forma, o volume de dados analisados. O MLME foi utilizado a partir do Interactive Data Language (IDL), linguagem implementada ao programa Environment for Visualizing Images (ENVI). Os modelos lineares são comumente utilizados para expressar a mistura de elementos dentro de um determinado pixel (QUINTANO et al., 2012):

$$
\begin{aligned}
& M f=f_{1} \mu_{1}+f_{2} \mu_{2}+\ldots+f_{c} \mu_{c} \\
& E(f)=f_{1} E_{1}+f_{2} E_{2}+\ldots+f_{c} E_{c}
\end{aligned}
$$

Nas equações 5 e $6, M$ (colunas x linhas) representa uma matriz em que as colunas são os vetores $\mu_{\mathrm{i}}, f(\mathrm{cx} 1)$ é o vetor que contém a proporção de cada endmember em determinado pixel e o vetor $\mu_{\mathrm{i}}$ representa o enésimo $\left(\mathrm{i}^{\text {th }}\right)$ endmember do espectro de reflectância de determinada banda. Do mesmo modo, $E$ representa os ruídos introduzidos no processo de formação da imagem em cada banda. Assim, pode-se considerar $E(f)$ independente de $f$, e o MLME pode ser expresso por:

$$
x=M f+e
$$

em que $e$ representa a proporção do vetor de erro previsto. Basicamente, duas alternativas podem ser utilizadas para resolver as equações do MLME (uma numérica e outra estatística). Porém, em ambos os casos, os algoritmos apresentam pouca influência nos resultados (QUINTANO et al., 2012). Desta forma, pode-se solucionar a equação 7 a partir de uma solução numérica básica:

$$
f=\left(M^{T} M\right)^{-1} M^{T} x
$$

Porém, para a solução deste sistema, é necessário incluir multiplicadores lagrangeanos (' $p$ ' parâmetros $\lambda=\left\{\lambda_{1}, \lambda_{2}, \ldots, \lambda_{p}\right\}$ ). Desta forma, a forma quadrática deve ser minimizada e pode ser descrita como:

$$
Q(x, f)=(x-M f)^{T} N^{-1}(x-M f)+2 \lambda^{T}(B f-T)
$$

em que B (pxc) representa uma matriz com os coeficientes de restrição e $T(p x 1)$ é a coluna que contém as restrições para o termo independente.

Após a aplicação do MLME no ENVI, todas as imagens fração sombra resultantes foram inseridas no Sistema de Processamento de Informações Georreferenciadas (SPRING 5.2) e segmentadas. Os limiares utilizados foram 12 para a similaridade e 20 para a área, e a partir dos polígonos originados na 
segmentação, foi realizada a edição topológica, onde foram atribuídos os polígonos das áreas queimadas às suas respectivas classes. A etapa final envolveu a edição manual do mapeamento com a finalidade de corrigir eventuais erros decorrentes da Classificação.

A edição manual consistiu na atribuição de áreas queimadas que não foram detectadas pelos critérios de similaridade e área, ou seja, erros de omissão. Neste caso, para cada área queimada que não possuía um polígono originado da segmentação, realizou-se um mapeamento manual. Ainda, pode-se constatar que não foram encontrados erros na segmentação, apenas áreas queimadas que não foram delimitadas neste processo.

\subsection{2 Índice de Área Foliar, Albedo da Superfície e Fração de Cobertura Vegetal}

Os dados referentes ao índice de área foliar foram extraídos dos produtos MYD15A2 (MODIS-AQUA) e MOD15A2 (MODIS-TERRA), que representam os índices de área foliar e a radiação fotossinteticamente ativa, obtidos a partir de um mosaico temporal de 8 dias e com $1 \mathrm{~km}$ de resolução espacial.

Os dados referentes ao albedo da superfície e à fração de cobertura vegetal foram obtidos em campo, realizado em Rondônia entre os dias 24 e 31 de agosto de 2013, onde foram percorridos diversos Municípios, como Porto Velho, Ariquemes, Alvorada do Oeste, São Miguel do Guaporé, Seringueiras, Ji-Paraná e Machadinho do Oeste.

Neste campo foi utilizado o FieldSpec Pro da Analytical Spectral Devices (ASD) para a coleta do fator de reflectância de alvos biofísicos da superfície, representados por áreas de corpos d'água, pastagens em diversos estágios, vegetação herbácea-arbustiva, vegetação arbórea, áreas agrícolas, solo exposto e queimadas em vários estágios (queimada recente e em estágio inicial e avançado de regeneração em diversos tipos de vegetação), e os pontos de coleta podem ser visualizados na Figura 1. Os procedimentos para a obtenção de todos os dados serão descritos a seguir.

\subsection{Medidas do fator de reflectância dos alvos e integração dos dados}

A Radiância (L) proveniente de um alvo pode ser considerada como a principal grandeza radiométrica para a obtenção de propriedades intrínsecas do objeto como, por exemplo, o espectro de reflectância (MILTON, 1987). Porém, para obter a reflectância espectral de determinado alvo a partir desta grandeza radiométrica, é necessário relacioná-la com a exitância radiante e a irradiância (E), algo raramente obtido em condições de campo. Desta forma, utiliza-se a padronização da radiância refletida de uma superfície por outra superfície perfeitamente difusa (lambertiana ideal) sobre as mesmas condições de irradiação (iluminação, $\theta$ ) e de geometria (observação, $\varphi$ ). 


$$
\rho_{\lambda}=\frac{\partial L_{\left(\theta_{r}, \phi_{r}, \lambda\right)} \pi}{\partial E_{\left(\theta_{i}, \phi_{i}, \lambda\right)}}=F R_{\left(\theta i, \phi i ; \theta_{o}, \phi_{o} ; \lambda\right)}=\frac{L a_{\left(\theta i, \phi i ; \theta_{o}, \phi_{o} ; \lambda\right)}}{L r_{\left(\theta i, \phi i ; \theta_{o}, \phi_{o} ; \lambda\right)}}
$$

em que $\rho_{\lambda}$ representa a reflectância espectral, $F R_{\lambda}$ é o fator de reflectância espectral estimado a partir da razão entre a radiância espectral da amostra $\left(L a_{\lambda}\right)$ pela radiância espectral de uma superfície lambertiana ideal $\left(L r_{\lambda}\right)$, nas mesmas condições de iluminação $(\theta)$ e observação $(\varphi)$.

Pode-se dizer que o fator de reflectância espectral equivale à reflectância espectral do alvo se mantidas a mesma geometria de observação e a mesma irradiância, como demonstrado abaixo (Milton, 1987):

$$
F R_{\lambda}=\frac{L a_{\lambda}}{L r_{\lambda}}, \text { sendo } \quad L_{\lambda}=\frac{\rho_{\lambda} E_{\lambda}}{\pi}
$$

Portanto, para uma superfície lambertiana ideal em que $\rho_{\lambda, r}=1(100 \%$ em todo o espectro eletromagnético solar), tem-se que:

$$
F R_{\lambda}=\frac{\rho_{\lambda, a} E_{\lambda} / \pi}{\rho_{\lambda, r} E_{\lambda} / \pi}=\frac{\rho_{\lambda, a}}{\rho_{\lambda, r}} \therefore F R_{\lambda}=\frac{\rho_{\lambda, a}}{1} \therefore F R_{\lambda}=\rho_{\lambda, a}
$$

No trabalho de campo, foi utilizado o equipamento FieldSpec Pro e uma placa Spectralon-11, desenvolvida em material sintético (polytetrafluoretileno) com reflectância espectral próxima a 100\% (JACKSON et al., 1992), que permitiu a obtenção do fator de reflectância espectral para diversos alvos terrestres de 350 a $2400 \mathrm{~nm}$. Devido às configurações do sistema e à utilização da irradiância solar, o fator de reflectância neste caso é bidirecional.

Uma vez que o modelo RegCM4 utiliza as informações do albedo da superfície, a radiação fotosinteticamente ativa (PAR) e a reflectância no infravermelho próximo e médio $\left(\rho_{\text {nir }+ \text { swir }}\right)$ foram integradas em seus respectivos comprimentos de ondas, conforme equação 13 e 14 :

$$
\begin{gathered}
P A R=\int_{350 n m}^{700 n m} F R_{\lambda} d \lambda \\
\rho_{\text {nir+swir }}=\int_{701 \mathrm{~nm}}^{2400 \mathrm{~nm}} F R_{\lambda} d \lambda
\end{gathered}
$$

Ressalta-se que na estimativa dos valores de $\rho_{\text {nir }+ \text { swir }}$, eliminaram-se os comprimentos de onda referentes às bandas de absorção do vapor d'água (1350- 
$1450 \mathrm{~nm}$ e 1800 a $1960 \mathrm{~nm}$ ). Ainda, a partir dos dados coletados em campo, foram estimadas as reflectâncias in-band $\left(\rho_{\text {in-band }}\right)$ para as bandas referentes à faixa do espectro eletromagnético do vermelho $(620-670 \mathrm{~nm})$ e do infravermelho próximo (841-876 nm) para o sensor MODIS, considerando na estimativa dos valores de reflectância a curva de sensibilidade espectral para cada banda. Neste procedimento, os valores de reflectância espectral são ponderados pela sensibilidade para cada comprimento de onda de acordo com a curva determinada em laboratório para cada banda. Sabe-se que durante o intervalo espectral de determinada banda, os detectores presentes no sensor ponderam a radiância espectral que sensibiliza os detectores de forma diferenciada, em geral, os comprimentos de onda centrais recebem um peso maior na composição da reflectância in-band que os comprimentos de onda das extremidades da banda, desta forma, este procedimento visa equiparar ambas medidas.

\subsection{Valores físico-químicos e biológicos estimados em campo}

Como visualizado na Figura 1, durante o período de 24 a 31 de agosto de 2013 foi realizado um trabalho de campo que tinha como objetivo avaliar os erros na metodologia de delimitação da área queimada e coletar parâmetros físico-químicos e biológicos dos principais usos e cobertura da terra utilizados pelo BATS para o Estado de Rondônia. Neste trabalho de campo, foram coletadas diversas amostras do fator de reflectância espectral bidirecional (aproximadamente 218) de pastagem seca, corpos hídricos, solo exposto, vegetação arbórea e herbácea e queimadas em três estágios (queimada recente, em estágio inicial de regeneração e em estágio avançado de regeneração).

Embora exista uma defasagem temporal entre as aquisições, os valores coletados em campo foram utilizados para atualizar os parâmetros físicos do modelo BATS, que se encontravam defasados e com características para florestas e outros tipos de uso e cobertura genéricos (determinados para o Globo) e não especificamente para a América do Sul. Neste caso, uma vez que o modelo RegCM4 simulou apenas o Estado de Rondônia, as parametrizações físicas do modelo utilizaram as características físicas da área de estudo, não influenciando, desta forma, nos resultados adquiridos.

Desta forma, o único procedimento metodológico que poderia influenciar nos resultados refere-se à aquisição de medidas de fator de reflectância espectral bidirecional em diferentes estágios de queimada, pois esta informação é a única que apresenta alteração entre a simulação de controle e a simulação com áreas queimadas. Porém, uma vez que foram coletadas mais de 84 amostras espalhadas por toda a área, pode-se dizer que a variabilidade em diversos tipos de queimada foi contemplada estatisticamente. Desta forma, presume-se que as estimativas de diferentes estágios de queimada podem ser aplicadas para os anos analisados, uma vez que é impossível obter informações mensais das propriedades físicas dos alvos. 


\subsection{Estimativa da fração de cobertura vegetal e dos valores do índice de área foliar}

Para estimar a fração de cobertura vegetal $(\mathrm{FCV})$ pode-se utilizar a relação entre o índice de vegetação por diferença normalizada (IVDN) para superfícies vegetadas e para o solo exposto (CARLSON; RIPLEY, 1997). Desta forma, o nível de cinza de uma imagem orbital pode ser considerado como uma proporção entre os elementos que compõem determinado pixel. Assim, $\mathrm{L}_{\lambda}$ de cada pixel pode ser descrita como o somatório das componentes de superfícies vegetadas $\left(\sigma_{\mathrm{v}}\right)$ e áreas não vegetadas $\left(1-\sigma_{\mathrm{v}}\right)$ :

$$
L_{\lambda}=L_{\lambda, v} \sigma_{v}+\left(1-\sigma_{v}\right) L_{\lambda, s}
$$

em que $L_{\lambda, v}$ representa a radiância espectral de áreas vegetadas e $L_{\lambda, s}$ a radiância espectral de superfícies não vegetadas. Neste contexto, pode-se calcular a FCV a partir de (CARLSON; RIPLEY, 1997):

$$
F C V=\frac{I V D N-I V D N_{s}}{I V D N_{v}-I V D N_{s}}
$$

em que o IDVN é estimado a partir dos dados de FR coletados em campo (em que s representa o valor do IVDN para o solo e v representa o valor do IVDN para a vegetação, 0,05 e 0,90 respectivamente) e convertidos para a $\rho_{\text {in-band. }}$. $\mathrm{O}$ índice de área foliar (IAF) foi obtido dos produtos MYD15A2 e MOD15A2 no ENVI a partir de um sorteio aleatório em áreas queimadas uma vez que estes dados apresentam contaminação por nuvens, o que não permite a estimativa da média do IAF diretamente nas imagens. Nestas áreas traçou-se um perfil temporal dos valores máximos e mínimos extraídos para cada ponto sorteado, gerando ao final a média dos valores.

\section{RESULTADOS E DISCUSSÃO}

As Figuras 2 e 3 mostram os mapas do uso e cobertura da terra e as áreas queimadas mapeadas nas imagens do sensor MODIS, utilizados na modelagem dos impactos das queimadas em Rondônia nos anos de 2000 a 2011. Percebe-se nas imagens que, de uma forma geral, o uso e cobertura da terra disponível do produto MCD12A1 do sensor MODIS é composto por áreas de vegetação arbórea, representada pela cor verde nos mapas, por áreas que compõem um mosaico de pastagens, agricultura e vegetação herbácea, representada pela cor amarela e por corpos d'água, representado pela cor azul.

Ainda, em vermelho destaca-se as áreas queimadas mapeadas nos 12 anos analisados. Podemos perceber que as queimadas apresentam uma variabilidade significativa e compreendem grandes extensões, especialmente na porção centro- 
norte, principalmente nos Municípios de Nova Mamoré, Porto Velho e Machadinho d'Oeste; no meio-leste do Estado, abrangendo principalmente os Municípios de Costa Marques e Seringueiras e no sul do Estado, localizadas em diversos Municípios, destacando-se grandes áreas queimadas em São Francisco do Guaporé, Alta Floresta, Alto Alegre e Pimenteiras.

Figura 2 - Mapas do uso e cobertura da terra e áreas queimadas mapeadas (A.Q.) em Rondônia nos anos de 2000 a 2005.

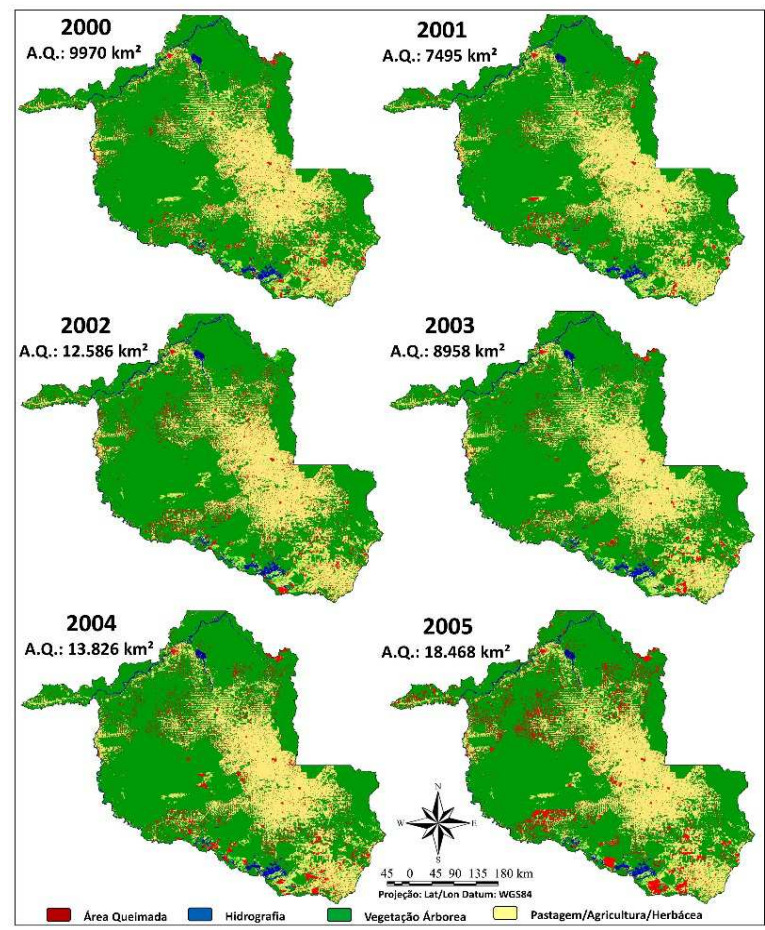

Desde o ano 2000, as ocorrências das queimadas apresentam oscilações, porém, de uma forma geral, pode-se notar um aumento até o ano de 2005, sendo que após esse ano houve uma diminuição gradativa até o ano de 2009 , ocorrendo um novo aumento significativo em 2010 e uma substancial diminuição no ano seguinte. De acordo com as Figuras 2 e 3, os anos que apresentaram as maiores ocorrências de queimadas (estimadas a partir das imagens de reflectância da superfície do sensor MODIS) foram $2005\left(18.468 \mathrm{Km}^{2}\right)$, compreendendo 7,7\% de todo o Estado, 2010 $\left(14.572 \mathrm{Km}^{2}, 6,13 \%\right)$ e $2004\left(13.826 \mathrm{Km}^{2}, 5,8 \%\right)$, e os anos que apresentaram as menores ocorrências foram $2009\left(4.916 \mathrm{Km}^{2}, 2 \%\right), 2011\left(5.730 \mathrm{Km}^{2}, 2,4 \%\right)$ e 2001 $\left(7.495 \mathrm{Km}^{2}, 3,1 \%\right)$. 
Figura 3 - Mapas do uso e cobertura da terra e áreas queimadas (A.Q.) mapeadas em Rondônia nos anos de 2006 a 2011.

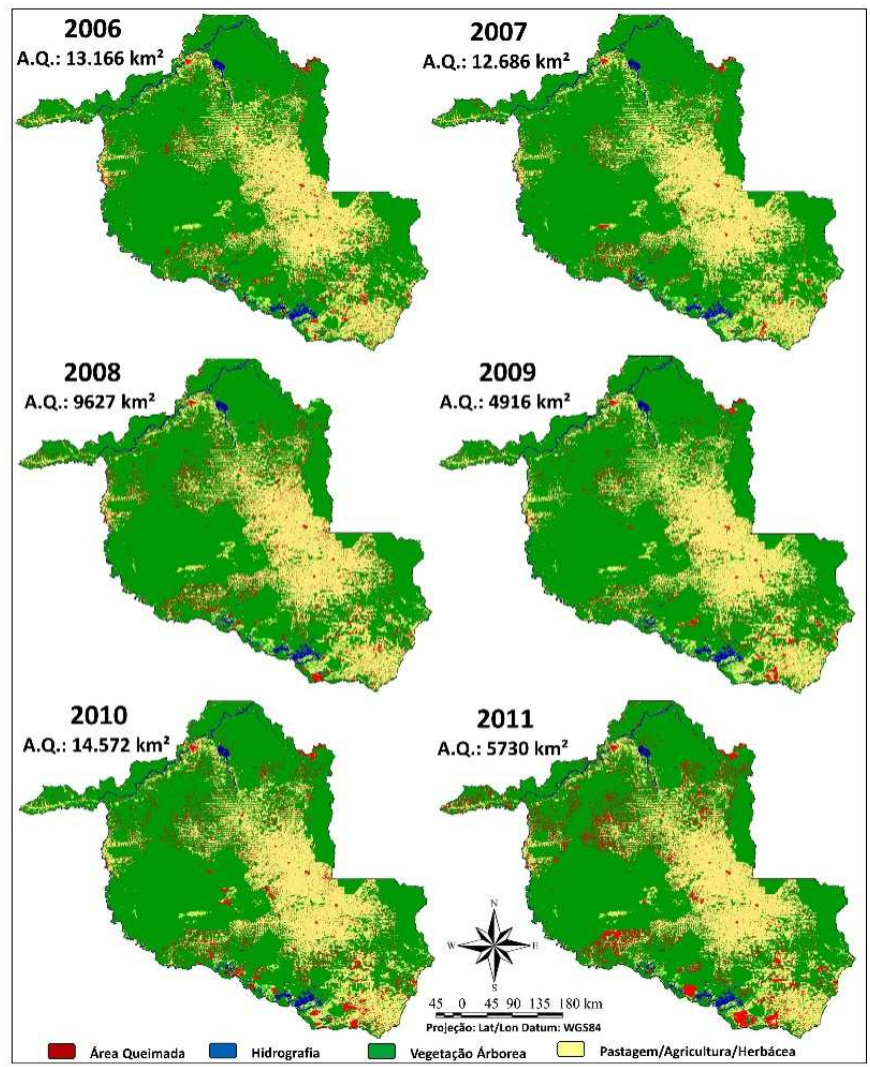

A Figura 4 mostra o gráfico do fator de reflectância de alvos da superfície coletados em Rondônia no trabalho de campo, composto por corpos hídricos, pastagem seca, vegetação arbórea e herbácea, solo exposto e queimadas em três estágios (queimada recente, em estágio inicial de regeneração e em estágio avançado de regeneração).

Neste gráfico percebe-se que a assinatura espectral da vegetação é bem característica, com um pequeno pico de reflectância na banda do verde na região do visível do espectro eletromagnético devido à realização da fotossíntese e valores elevados de reflectância na região do infravermelho próximo devido aos componentes internos da folha. Os valores centrados em 1400 e $1800 \mathrm{~nm}$ referem-se à bandas de absorção do vapor d'água pela atmosfera e foram retirados da análise por apresentarem apenas ruídos devido à ausência de irradiância na superfície. 
Figura 4 - Gráfico do fator de reflectância de alvos biofísicos da superfície coletados em Rondônia.

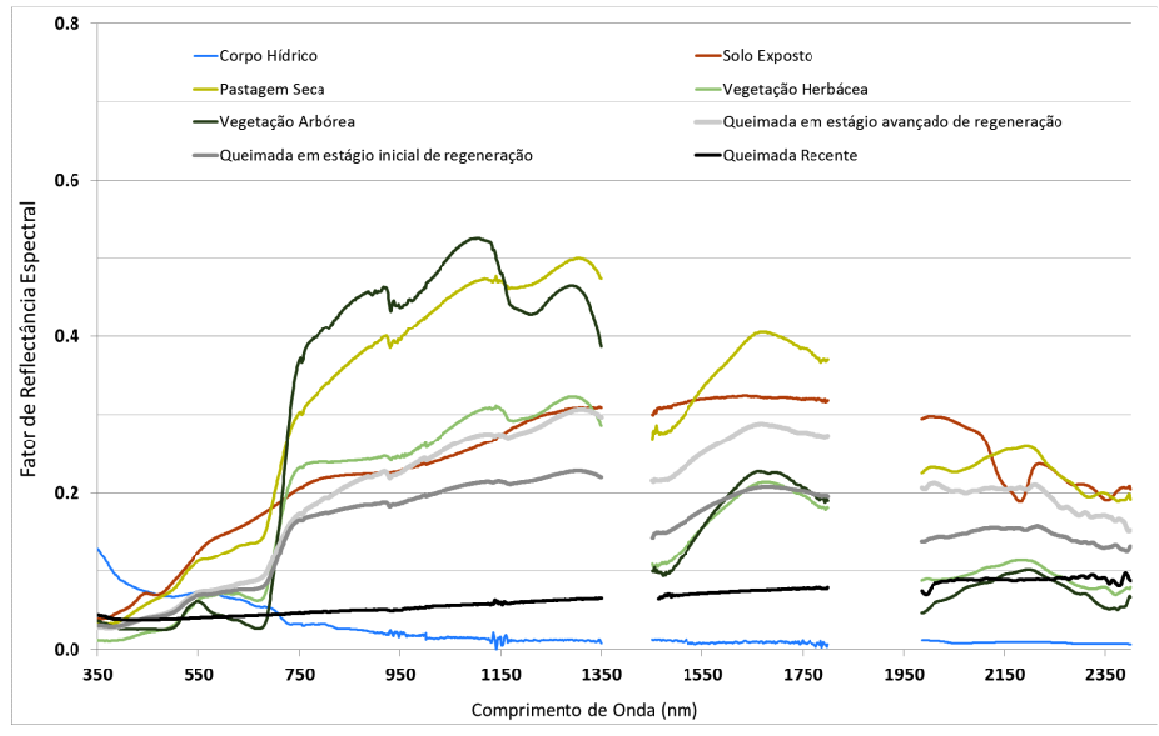

Na Figura 4 pode-se perceber que na ocorrência de uma queimada recente o fator de reflectância apresenta uma substancial diminuição devido à perda de material fotosinteticamente ativo da vegetação verde e pelo depósito de cinzas e carvão sobre o solo, denotando um elevado contraste entre a vegetação queimada e a não queimada. Em relação às queimadas em regeneração, percebe-se que o fator de reflectância retorna a apresentar a assinatura espectral similar da vegetação, devido a recomposição da estrutura vegetal, porém, com aumento da reflectância em comprimentos de onda superiores a $1450 \mathrm{~nm}$ devido à influência do solo no comportamento espectral coletado.

Outra análise pode ser realizada a partir do albedo, que é definido pela reflectância integrada em todas as faixas do espectro eletromagnético, portanto, após uma queimada, ocorre uma grande diminuição na reflectância espectral da superfície, consequentemente diminuindo o albedo. Analisando o gráfico da Figura 4, constata-se que o albedo da vegetação arbórea é de aproximadamente $22 \%$, entretanto, ao queimar a vegetação os valores de albedo diminuem para $6 \%$, denotando que nessas áreas a radiação solar é quase totalmente absorvida (94\%), porém, no momento em que a área queimada inicia o processo de regeneração, os valores de albedo aumentam para $16 \%$ e $20 \%$, indicando uma maior contribuição de pequenas áreas vegetadas e de solo exposto sem cinzas.

A partir das informações obtidas em campo e estimadas a partir de produtos orbitais, alteraram-se os valores de entrada do modelo regional RegCM4 e simularam-se as principais alterações ocorridas nas variáveis meteorológicas. $\mathrm{O}$ 
resultado das diferenças nas simulações (controle-queimada) é apresentado na Figura 5, que mostra as mudanças ocorridas no balanço de radiação de ondas curtas devido à influência das queimadas no Estado de Rondônia (2000 a 2011).

Figura 5 - Mudanças ocorridas no balanço de radiação de ondas curtas devido às queimadas no Estado de Rondônia (2000 a 2011).

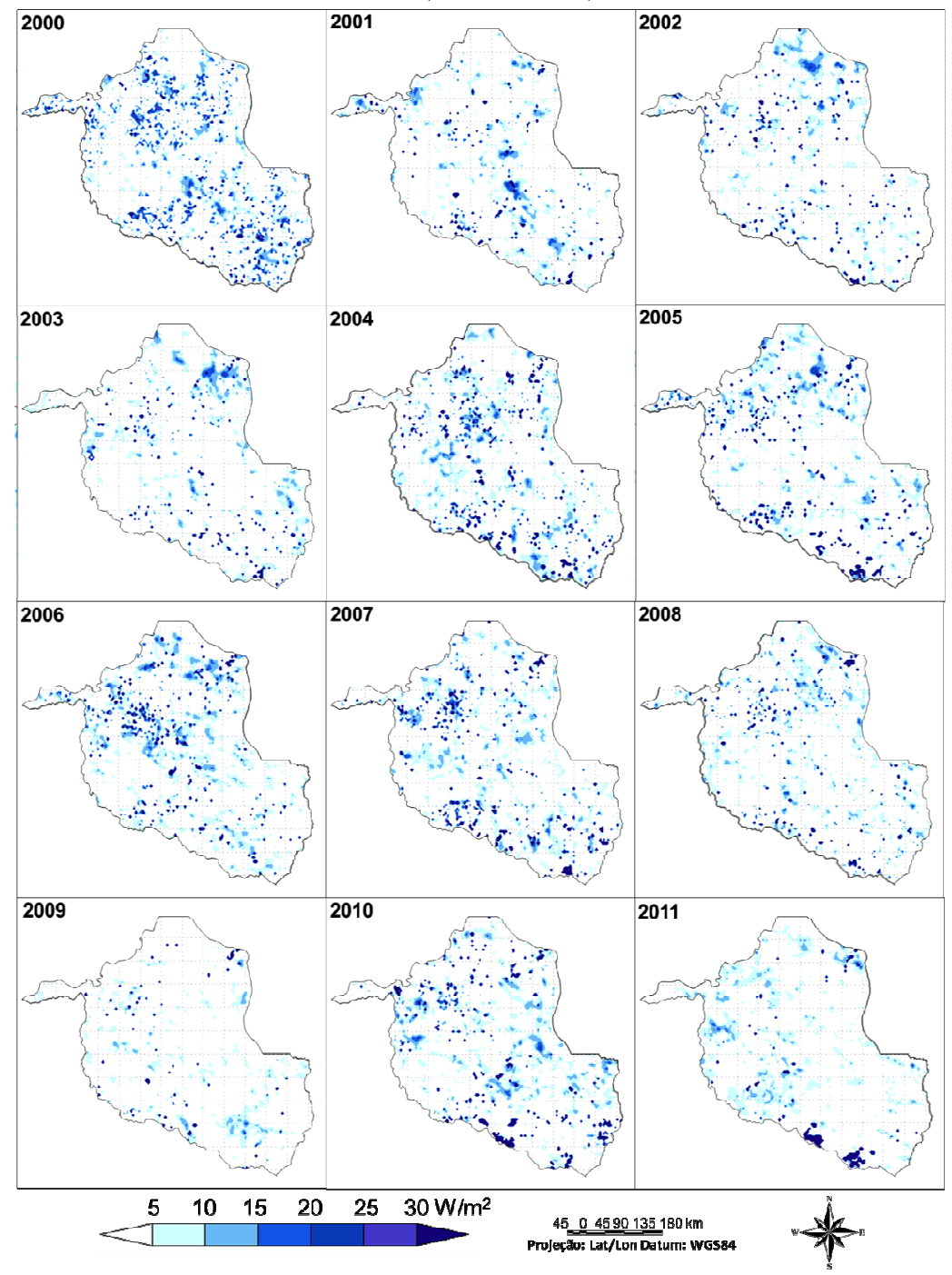

Bol. Ciênc. Geod., sec. Artigos, Curitiba, v. 20, nº 4, p.830-854, out-dez, 2014. 
O saldo de radiação de ondas curtas é definido pela diferença entre a radiação de ondas curtas que incide na superfície terrestre (irradiância solar) e a radiação de ondas curtas que é refletida. Após uma queimada ocorre uma grande diminuição na reflectância espectral da superfície, causando a diminuição do albedo, e este fator provoca o aumento da absorção da irradiância solar pelas cinzas.

Desta forma, a diminuição do albedo provoca modificações no balanço de radiação de ondas curtas, como pode ser constatado na Figura 5. Na área de estudo as queimadas provocam em geral um aumento na absorção da irradiância incidente que pode ser superior a $30 \mathrm{~W} / \mathrm{m}^{2}$ em média, podendo chegar a valores máximos absolutos de $90 \mathrm{~W} / \mathrm{m}^{2}$ em áreas onde as queimadas foram mais extensas e intensas, principalmente em locais com queimadas mais recentes, como nas áreas que apresentam grande quantidade de queimadas na região norte e no centro do Estado e nas áreas que apresentam grandes cicatrizes localizadas na região sul. As maiores variações podem ser visualizadas nos tons azuis mais escuros nos mapas anuais, coincidindo com as cicatrizes de queimadas mapeadas, destacando-se os anos de 2000, 2004, 2005, 2006, 2007 e 2010 como os anos que apresentaram as maiores variações.

Apesar do ano 2005 apresentar as maiores ocorrências de queimadas em todo o período estudado, percebe-se que a variação no balanço de radiação de ondas curtas não foi tão expressiva comparada com o ano 2000, por exemplo. Uma vez que o modelo leva em consideração todos os fatores meteorológicos em sua simulação, o fato de um ano apresentar uma quantidade maior de nuvens pode influenciar no total de irradiância solar absorvida pela superfície. Desta forma, a diferença entre a simulação de controle e queimada pode apresentar diferenças sutis.

Neste contexto, a maior absorção da irradiância solar ocasiona alterações nas trocas de calor e faz com que a temperatura aumente na superfície, como pode ser visualizado na Figura 6. Assim, percebe-se que as modificações no albedo da superfície e por consequência no balanço de radiação de ondas curtas ocasionam o aumento da temperatura no solo, que em média obtiveram um aumento que pode ultrapassar $1,5^{\circ} \mathrm{C}$ por dia, representados na cor vermelho escuro dos mapas, com destaque para os anos 2005, 2010, 2002, 2006 e 2008, anos na qual a quantidade de área queimadas foi superior aos demais anos. Ainda, ao analisar o perfil das temperaturas máximas da superfície ocorridas durante o dia na área de estudo, percebe-se que as mesmas podem atingir um valor máximo absoluto que chega a $18^{\circ} \mathrm{C}$ de variação dependendo da área que foi queimada (em relação à simulação controle, na qual as áreas são consideradas sem queimada). 
Figura 6 - Mudanças ocorridas na temperatura do solo devido às queimadas no Estado de Rondônia (2000 a 2011).

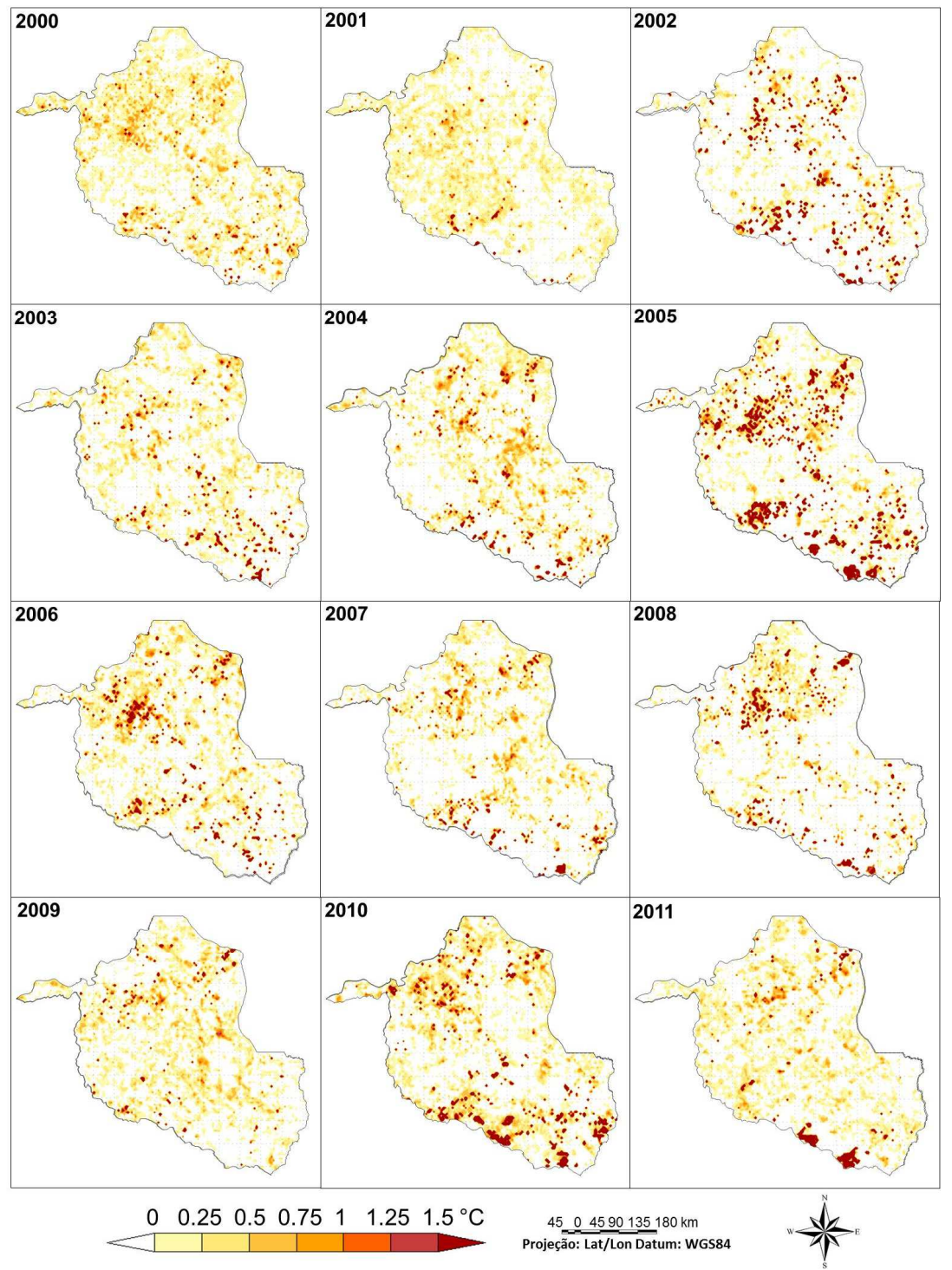

As áreas que apresentam as maiores modificações na temperatura da superfície estão localizadas de uma forma geral em uma extensa área da região central norte e na região leste no centro do Estado, destacando a ocorrência de cicatrizes maiores

Bol. Ciênc. Geod., sec. Artigos, Curitiba, v. 20, nº 4, p.830-854, out-dez, 2014. 
no sul do Estado, sempre relacionadas e coincidindo com as queimadas de maior intensidade. Neste contexto, de acordo com o mapa do uso da terra atual do IBGE (2011), foi identificado que as queimadas ocorrem em maioria em áreas de extrativismo vegetal, abrangendo $14.995 \mathrm{~km}^{2}$, seguida por áreas de pecuária de animais de grande porte e cultivos permanentes diversificados $\left(14.525 \mathrm{~km}^{2}\right)$ e por áreas exclusivas de animais de grande porte $\left(12.409 \mathrm{~km}^{2}\right)$, evidenciando que o uso da terra é o maior responsável pelas modificações e impactos em Rondônia.

Desta forma, percebe-se que todos os parâmetros físicos da superfície estão interligados, e as modificações provocadas pelas queimadas em apenas um deles podem influenciar todos os outros parâmetros, e a mudança no uso da terra é um fator essencial na modificação da circulação atmosférica local, uma vez que está diretamente relacionada com a alteração do balanço de radiação e, consequentemente, com o balanço de energia. Assim, a diminuição no albedo da superfície por consequência altera o balanço de radiação de ondas curtas devido ao aumento da absorção da radiação incidente, provocando um maior aquecimento e o aumento da temperatura na superfície. Neste contexto, o aumento da temperatura da superfície também provoca alterações na temperatura do ar, conforme pode ser verificado na Figura 7.

Figura 7 - Gráfico da anomalia da temperatura em diversos níveis da atmosfera no Estado de Rondônia.

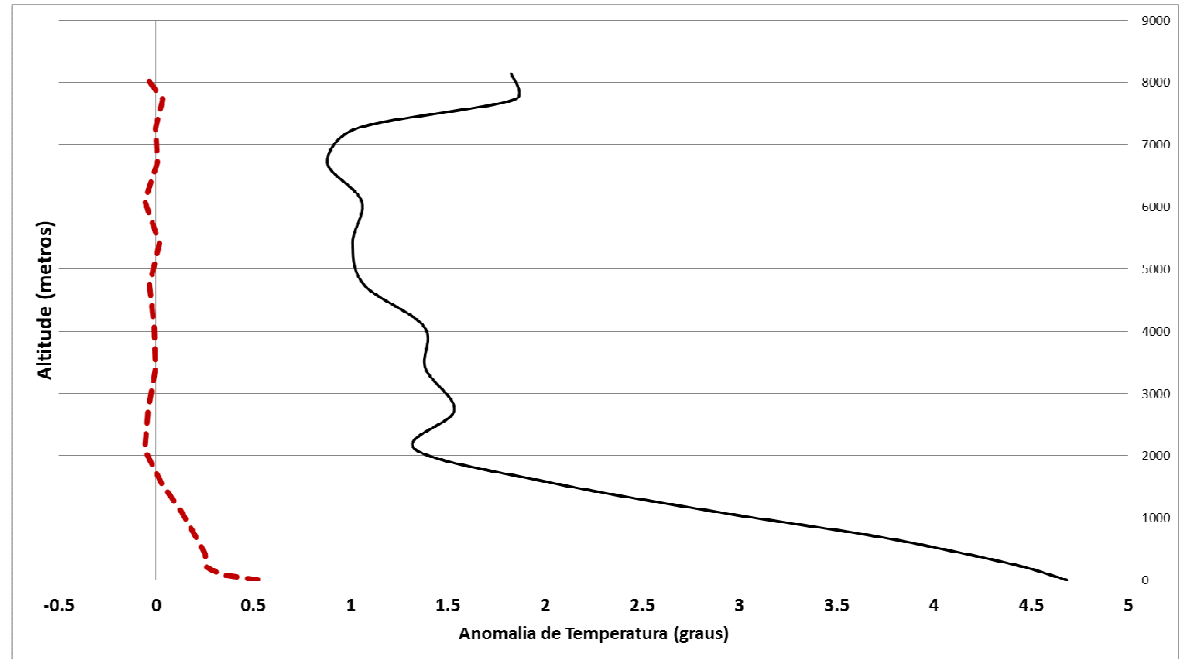

A Figura 7 mostra o gráfico da anomalia da temperatura distribuída em diversos níveis da atmosfera. Neste caso foram selecionados 5 pontos em áreas queimadas para cada ano e a média da temperatura total diária foi gerada. A linha vermelha tracejada representa a média diária da temperatura e a linha preta 
representa a variação máxima da anomalia da temperatura do ar nas camadas atmosféricas que ocorre durante o dia (produto originado da diferença entre a modelagem controle-queimadas).

Percebe-se que, em média, a temperatura do ar na superfície apresenta um aumento médio de $0,5^{\circ} \mathrm{C}$, e dependendo da intensidade da queimada, a diferença entre as duas simulações (controle-queimada) pode atingir quase $5^{\circ} \mathrm{C}$. Ao analisar a variação da temperatura do ar em altitude entre as duas simulações, percebe-se que a $1000 \mathrm{~m}$ a temperatura do ar apresenta um aumento de $0,3{ }^{\circ} \mathrm{C}$ em média, sendo que nas áreas que apresentam grandes cicatrizes esse aumento pode chegar a $3{ }^{\circ} \mathrm{C}$ devido à convecção do ar. Na altitude de $2000 \mathrm{~m}$ percebe-se que os valores médios da temperatura do ar sofrem pouca variação, principalmente quando a cicatriz possui pouca extensão, porém dependendo da intensidade da queimada as temperaturas máximas podem atingir um aumento de $1,5^{\circ} \mathrm{C}$ neste nível. Assim, nota-se que as queimadas ocasionam alterações significativas não só na temperatura do solo e por consequência do ar, mas em diversas variáveis climatológicas, como nos fluxos de calor latente e sensível e na evapotranspiração, fatores que quando somados podem alterar o clima local e regional.

\section{CONCLUSÃO}

Percebe-se neste trabalho que as queimadas apresentam uma variabilidade significativa no Estado de Rondônia e abrangem grandes extensões anualmente, com destaque para os anos de 2005, compreendendo 7,7\% de todo o Estado, 2010 $(6,13 \%)$ e $2004(5,8 \%)$. Neste contexto, foi identificado que as queimadas ocorrem em maioria em áreas de extrativismo vegetal, áreas de pecuária de animais de grande porte e de cultivos permanentes diversificados, evidenciando que o uso da terra é o maior responsável pelas modificações e impactos em Rondônia.

Assim, na ocorrência de uma queimada foi constatado que os valores de albedo diminuem $16 \%$ em relação à vegetação não queimada, denotando que nessas áreas a irradiância solar é quase totalmente absorvida pelas cinzas na superfície. Este fator provoca modificações no balanço de radiação de ondas curtas, os quais apresentaram valores médios de $30 \mathrm{~W} / \mathrm{m}^{2}$, devido à maior absorção da irradiância solar na superfície, causando alterações nas trocas de calor e consequentemente aumentando a temperatura do solo, que apresentaram valores médios de $1,5^{\circ} \mathrm{C}$ por dia e valores máximos absolutos que podem atingir $18^{\circ} \mathrm{C}$ dependendo da área que foi queimada.

Desta forma, o aumento da temperatura do solo provocou o aumento da temperatura do ar, apresentando em $1000 \mathrm{~m}$ valores da ordem de $0,3{ }^{\circ} \mathrm{C}$ em média e nas áreas que apresentam grandes cicatrizes esse aumento pode chegar a $3^{\circ} \mathrm{C}$ devido à convecção do ar, sendo que a $2000 \mathrm{~m}$ os valores médios da temperatura do ar sofrem pouca variação, principalmente quando a cicatriz possui pouca extensão, porém dependendo da intensidade da queimada as temperaturas máximas podem atingir um aumento de $1,5^{\circ} \mathrm{C}$ neste nível. 
Desta forma, percebe-se que todos os parâmetros físicos da superfície estão interligados, e as modificações provocadas pelas queimadas em apenas um deles podem influenciar todos os outros parâmetros, e a mudança no uso da terra é um fator essencial na modificação da circulação atmosférica local, uma vez que está diretamente relacionada com a alteração do balanço de radiação e, consequentemente, com o balanço de energia. Assim, nota-se que as queimadas ocasionam alterações significativas não só na temperatura do solo e por consequência do ar, mas em diversas variáveis climatológicas, como nos fluxos de calor latente e sensível e na evapotranspiração, fatores que quando somados podem alterar o clima local e regional.

\section{AGRADECIMENTOS:}

À Fundação de Amparo à Pesquisa do Estado de São Paulo (FAPESP) pelo apoio (2010/17437-4).

\section{REFERÊNCIAS BIBLIOGRÁFICAS}

ANDREAE, M. O.; MERLET, P. Emission of trace gases and aerosols from biomass burning, Global Biogeochem. Cycles, v. 4, n. 15, p. 955-966, 2001.

BATISTA, I.X. Desenvolvimento em Rondônia: Politicas Públicas, Desmatamento e Evolução Socioeconômica. 2001. 172 p. Dissertação (Mestrado em Geociências e Meio Ambiente) - Universidade Federal de Rio Claro, Rio Claro, 2001.

BOWMAN, D. M. J. S.; BALCH, J. K.; ARTAXO, P.; BOND, W. J.; CARLSON, J. M.; COCHRANE, M. A.; D'ANTONIO, C. M.; DEFRIES, R. S.; DOYLE, J. C.; HARRISON, S. P.; JOHNSTON, F. H.; KEELEY, J. E.; KRAWCHUK, M. A.; KULL, C. A.; MARSTON, B.; MORITZ, M. A.; PRENTICE, C.; ROOS, C. I.; SCOTT, A. C.; SWETNAM, T. W.; WERF, G. R. V.; PYNE, S. J. Fire in the Earth System, Science, v. 324, p. 481-484, 2009.

CARDOSO, M.; NOBRE, C.; SAMPAIO, G.; HIROTA, M.; VALERIANO, D.; CÂMARA, G. Long-term potential for tropical-forest degradation due to deforestation and fires in the Brazilian Amazon. Biologia (Bratislava), v. 64, p. 433-437, 2009.

CARLSON, T. N.; RIPLEY, D. A. On the relation between NDVI, fractional vegetation cover, and leaf area index. Remote Sensing of Environment, v. 62, p. 241-252, 1997.

CARDOSO, M.; NOBRE, C.A.; LAPOLA, D.; OYAMA, M.D.; SAMPAIO, G.Long-term potential for fires in estimates of the occurrence of savannas in the tropics. Global Ecology and Biogeography, v. 17,p. 222-235, 2008.

CHARLSON, R. J.; ORIANS, G. H.; WOLFE, G. V.; BUTCHER, S. S. Human Modification of Global Biogeochemical Cycles. International Geophysics, v. 50, p. 353-361, 1992. 
CRUTZEN, P. J.; ANDREAE, M. O. Biomass burning in the tropics: impact on atmospheric chemistry and biogeochemical cycles. Science, v. 250, p. 16691678, 1990.

CUADRA, S. V.; ROCHA, R. P. Simulação Numérica do Clima de Verão Sobre o Sudeste do Brasil e sua Variabilidade. Revista Brasileira deMeteorologia, 21, p. 271-282, 2006.

DICKINSON, R. E.; KENNEDY, P. J.; HENDERSON-SELLERS, A.; Wilson, M. Biosphere-atmosphere transferscheme (bats) for the ncar community climate model. Tech. Rep. NCARE/TN-275+STR, National Centerfor Atmospheric Research, 1986.

DICKINSON, R. E.; ERRICO, R. M.; GIORGI, F.; BATES, G. T. A regional climate model for the western United States. Climatic Change, v. 15, p. 383422, 1989.

DRUYAN, L. M.; FULAKEZA, M.; LONERGAN, P. Dynamic downscaing of seasonal climate predictions over Brazil. J. Clim., v. 15, p. 3411-3426, 2002.

EMANUEL, K. A. A scheme for representing cumulus convection in large-scale models. Journal of the Atmospheric Sciences, v. 48, p. 2313-2335, 1991.

FEARNSIDE, P. M.; RIGHI, C. A.; GRAÇA, P. M. L. A.; KEIZER, E. W. H.; CERRI, C. C.; NOGUEIRA, E. M.; BARBOSA, R. I. Biomass and greenhouse gas emissions from land-use change in Brazil's Amazonian "arc of deforestation": The states of Mato Grosso and Rondônia. Forest Ecology and Management, v. 258, p. 1968-1978, 2009.

FREITAS, S.R.; LONGO, K.M.; DIAS, M.A.F.S.; DIAS, P.L.S.; CHATFIELD, R.; PRINS, E.; ARTAXO, P.; GRELL, G.A.; RECUERO, F.S. Monitoring the transport of biomass burning emissions in South America. Environmental Fluid Mechanics, v. 5, p. 135-167, 2005.

FRITSCH, J. M.; Chappell, C. F. Numerical prediction of convectively driven mesoscale pressuresystems. part i: Convective parameterization. J. Atmos. Sci., v. 37, p. 1722-1733, 1980.

GIORGI, F. Two-dimensional simulations of possible mesoscale effects of nuclear war fires. J. Geophys.Res., v. 94, p. 1127-1144, 1989.

HOLTSLAG, A. A. M.; Bruijn, E. I. F.; Pan, H. L. A high resolution air mass transformation model for short-range weather forecasting. Mon. Wea. Rev., v. 118, p. 1561-1575, 1990.

HOUGHTON, J. T.; DING. Y.; GRIGGS, D. J.; NOGUER, M.; LINDEN, P. J. VAN DER ; DAI, X.; MASKELL, K.; JOHNSON, C. A. Climate change 2001: the scientifc basis. Cambridge, U.K.: Cambridge University Press, 881 p, 2001.

IBGE - Instituto Brasileiro de Geografia e Estatística. Manual Técnico da Vegetação Brasileira. Rio de Janeiro, 2012.

ICHOKU, C.; KAUFMAN, Y. J. A method to derive smoke emission rates from MODIS fire radiative energy measurements, IEEE Trans. on Geosc. \& Rem. Sens., v. 43, n. 11, p. 2636-2649, 2005. 
JACKSON, R. D.; CLARKE, T.R.; MORAN, M.S. Bidirectional Calibration Results for 11 Spectralon and $16 \mathrm{BaSO}_{4}$ Reference Reflectance Panels. Remote Sensing of Ennvironment, v. 40, p. 231-239, 1992.

QUINTANO, C.; FERNÁNDEZ-MANSO, A.; SHIMABUKURO, Y.E. ; PEREIRA, G. Spectral unmixing. International Journal of Remote Sensing, v. 33, p. 5307-5340, 2012.

LIANG, S. Narrowband to broadband conversions of land surface albedo I algorithms. Remote Sensing of Environment, v. 76, p. 213-238, 2000.

LIU, Y. Q.; AVISSAR, R.; GIORGI, F. A simulation with the regional climate model RegCM2 of extremely anomalous precipitation during the 1991 East Asian flood: An evaluation study. J. Geophys. Res., v. 101, p. 26199-26216, 1996.

LIU, Y. Atmospheric response and feedback to radiative forcing from bio-mass burning in tropical South America. Agricultural and Forest Meteorology,

v. 133(1-4), p. 40-53, 2005.

MARENGO, J.A.; NOBRE, C.; SALAZAR, L.F. Regional Climate Change cenarios in South America in the Late XXI Century: Projections and Expected Impacts. Nova Acta Leopoldina, v. 112,p. 251-265, 2010.

MILTON E.J. Principles of field spectroscopy, International Journal of Remote Sensing, v. 8 n.2, p. 1807-1823, 1987.

OLESON, K. Technical description of the Community Land Model (CLM). Tech. Rep. Technical Note NCAR/TN-461+STR, NCAR, 2004.

PEREIRA, E. B.; MARTINS, F. R.; ABREU, S. L.; COUTO, P.; STUHLMANN, R.; COLLE, S. Effects of burning of biomass on satellite estimations of solar irradiation in Brazil. Solar Energy, v. 68, Issue 1, p. 91-107, 2000.

ROCHA, R. P.; MORALES, C. A.; CUADRA, S. V.; AMBRIZZI, T. Precipitation diurnal cycle and summer climatology assessment over South America: An evaluation of Regional Climate Model version 3 simulations. J. Geophys. Res., v. 114, 2009.

SAMPAIO, G.; NOBRE, C.; COSTA, M.H.; SATYAMURTY, P.; SOARESFILHO, B.S.; CARDOSO, M.F. Regional climate change over eastern Amazonia caused by pasture and soybean cropland expansion. Geophysical Research Letters, v. 34, p. 1-7, 2007.

SILVA, J.M.; LINHARES, D.P.; NUNES, D.D.; ASSUNÇÃO, A.G.; LIMA, T.R.; FURLAN, D.N.; CARVALHO, A.C.; SOUZA, R.C. Evolution of Deforestation and Natural Resources Degradation in Rondônia. Sociedade \& Natureza, Special Issue, p. 502-511, 2005.

TUMMON, F.; SOLMON, F.; LIOUSSE, C.; TADROSS, M. Simulation of the direct and semidirect aerosol effects on the southern Africa regional climate during the biomass burning season, J. Geophys. Res., v. 115, 2010.

VAN DER WERF, G.R.; RANDERSON, J.T.; GIGLIO, L.; COLLATZ, G.J.; KASIBHATLA, P.S.; ARELLANOJR., A.F. Interannual variability in global 
biomass burning emissions from 1997 to 2004, Atmospheric Chemistry and Physics, v.6,p. 3423-3441, 2006.

ZHANG, Y. Influences of Biomass Burning on Land-Atmosphere Interactions and Dry-to-Wet Transition over Amazônia. 2005. 48 p. Tese (Science in School of Earth and Atmospheric Sciences) - Georgia Institute of Technology, Georgia, 2005.

(Recebido em abril de 2014. Aceito em agosto de 2014). 